\title{
FEMINISMO GORDO: SEXO, DESEJO E PRAZERES REVOLUCIONÁRIOS
}

\author{
FAT FEMINISM: SEX, DESIRE AND REVOLUCIONARY PLEASURES
}

\begin{abstract}
RESUMO
No capitalismo contemporâneo, a ação biopolítica alimenta discursos de poder e disciplina à sexualidade e tecnologias que normatizam identidades e corporeidades possíveis nas práticas sexuais heteronormativas como regime político e tecnológico na reprodução de corpos. Este texto visa repensar as formas subalternas de sobrevivência, a partir de literaturas contemporâneas cuir que rompam com o pré-estabelecido em relação à sexualidade e ao feminismo gordo, os quais propõem a desobediência ao sistema sexual-político hegemônico de caráter colonizador, desestabilizando essa lógica de corporeidades patologizadas sobre mulheres gordas. A proposta é denunciar uma injustiça epistemológica sobre esses corpos gordos e a construção do desejo que os classifica como desejáveis enquanto saudáveis, e os indesejáveis enquanto doentes e perversos, a partir de uma nova proposta revolucionária de sexo, desejo e prazeres.
\end{abstract}

Palavras-chave: Feminismo Gordo. Prazeres Revolucionários. Sexopolítica. Epistemologias Subalternas.

\begin{abstract}
In contemporary capitalism biopolitical action feeds discourses of power and discipline- about sexuality and technologies that normalize possible identities and corporealities in heteronormative sexual practices, as a political and technological regime in the replication of bodies. This text aims to rethink subordinate forms of survival, based on contemporary literatures that break the pre-established in relation to sexuality and fat feminism, which proposes disobedience to the hegemonic sexual-political system with a colonizing characteristic, breaking this logic about pathological corporealities about fat women. The proposal is to denounce an epistemological injustice about these fat bodies and the construction of desire, which classify desirable bodies as healthy, and undesirable bodies as sick and perverse, in a new revolutionary proposal of sex, desire and pleasures.
\end{abstract}

Keywords: Fat Feminism. Revolutionary Pleasures. Sex-politics. Subaltern Epistemologies.

Maria L. J. Jimenez

Doutora em Estudos de Cultura Contemporânea pela UFMT, Brasil. E-mail: malujjimenez@gmail.com Marcelle J. da Silva

Doutora em Sociologia pela UFC, Brasil. E-mail: marcelle.silva.cs@gmail.com 


\section{Introdução}

O que significa ter um corpo desejável e causar desejo na sociedade capitalista contemporânea, heteronormativa, centrada numa construção de discursos soberanos sobre sexo e das tecnologias de normalização das identidades e corpos sexuais?

Meu corpo gordo nunca vai ser desejado sexualmente dentro dessa lógica heterocentrada, onde é construído desde as infâncias um regime político que coloca a sexualidade dentro de uma lógica dualista entre desejado e repugnante, já que como mulher gorda meu corpoéabjeto e nunca está associado dentro desse mecanismo patriarcal que impõe protótipos de corpas para serem desejadas e/ou sentir desejo. Eu sou subversiva e desobedeço sexualmente a esta construção, porque minha sexualidade é política (Malu, 49 anos, 2021).

Pensando nessa pergunta e nesse depoimento, decidimos entre duas mulheres gordas pesquisadoras, que se debruçam sobre os Estudos transdisciplinares do Corpo Gordo no Brasil e fazem ativismo, trazer uma revisão crítica bibliográfica sobre esse sistema heteronormativo, o qual se trata de um regime político, que é produto e produtor de tecnologias de reprodução de corpos obedientes. A ideia central de nossa proposta é compartilhar o entendimento de que existem formas subalternas de sobrevivência, de desejar e ser desejada numa proposta cuir, como objeto de pensamento de uma multidão de corpos anormais, que se diferenciam de uma normalidade sistêmica como forma de controle de nossa sexualidade no mundo.

Encontramos, na compreensão do filósofo Paul Preciado (2018), a respeito da cultura ocidental contemporânea, um ponto de partida para a discussão que desenvolvemos nesse artigo, no sentido de que vivemos em uma "era farmacopornográfica", com base em sua teoria sobre como o capitalismo nos afeta individual e coletivamente, através da fabricação, gestão e promoção dos corpos em escala global. O corpo, sempre "farmacopornográfico", a partir dessa lógica particular, está em constante e ininterrupta vigilância, sobretudo a partir da Segunda Guerra Mundial, época em que se instaura um novo "regime pós-industrial, global e midiático" que aciona "processos de governo biomolecular (fármaco) e semiótico-técnico (pornô)" (PRECIADO, 2018, p. 36) de controle "biomidiático" da subjetividade e, consequentemente, do corpo, transformando-o em normalidade a cisgeneridade - "conceito que abarca as pessoas que se identificam com o gênero que lhes foi determinado quando de seu nascimento, ou seja, as pessoas não-transgênero" (VERGUEIRO, 2015, p. 44), a heterossexualidade e a branquitude.

As tecnologias sociais, que são pilares dessa nova roupagem capitalística, nomeadas por Preciado (2018, p. 54) de "biocapitalismo farmacopornográfico", estão envolvidas nas dinâmicas das indústrias do sexo, pornográfca, farmacêutica

1 Depoimento de uma das autoras. 
e audiovisual. As transformações decorrentes da consolidação, expansão e penetrabilidade dessas indústrias inauguraram uma nova época de "gestão política e técnica do corpo, do sexo e da sexualidade" a partir do desenvolvimento de "novas dinâmicas do tecnocapitalismo avançado, da mídia global e das biotecnologias", transformando em principais matérias-primas "o saber, a informação, a comunicação e as relações sociais.” (PRECIADO, 2018, p. 39). Essas mesmas tecnologias desenvolvem um "trabalho social heteronormativo" (PRECIADO, 2014, p. 143) que consiste na invenção do sujeito hegemônico, socialmente valorizado e aceito, codificado como masculino, cisgênero, branco, heterossexual e consumidor "de serviços sexuais pauperizados (frequentemente exercidos por corpos codificados como femininos, infantis ou racializados)".

Essa dinâmica sociocultural eleva o sujeito hegemônico como o padrão a ser seguido e também como o ponto de partida para a classificação da normalidade, detentor do poder sobre os outros, que são, consequentemente, marginalizados, subalternizados e inferiorizados (tais como: as mulheres, as crianças, as pessoas não brancas e pessoas transgêneras), e esse poder transforma os corpos em sexuais e desejáveis, voltados para seu consumo, codificados enquanto "fontes carnais e digitais de capital ejaculatório." (PRECIADO, 2018, p. 52).

Nessemomentodenossahistória,a“hipervalorizaçãodocorpo"(GOLDENBERG, 2007, p. 10) é normalizada, assim como a obsessão com a corporalidade. Segundo essa lógica que, não por acaso, hipervaloriza apenas um tipo de corpo - o magro -, "somos responsabilizadas pela nossa aparência física, pelos nossos sucessos e fracassos pessoais e profissionais" e, já que o corpo pode ser "modificado simbólica e materialmente", cabe a nós, portanto, o "autocontrole" daquilo que a sociedade entende como "fora da norma" (SILVA, 2019, p. 16) e excesso.

Se não conseguimos corresponder a esta, que é uma expectativa social, somos duplamente marginalizadas: por não estarmos dentro do padrão e por escolhermos permanecer fora dele. De acordo com a proposta de Preciado (2018, p. 55), se somos posicionadas fora do padrão e da expectativa socialmente estabelecida, nossas vidas não são "suscetíveis de produzir benefício ejaculatório", isto é, de ser objeto de consumo e, consequentemente, de prazer para o sujeito hegemônico. Deste modo, é como se não existíssemos.

As tecnologias, às quais nos referimos há pouco, são chamadas por Preciado (2014; 2018) de tecnologias sexopolíticas, por agirem diretamente sobre nossos corpos e sexualidades, que impõem normas e dinâmicas limitadoras e insistentes na produção de "sujeitos-heterovaginais". (PRECIADO, 2018, p. 38). Butler (2014, p. 253-254) afirma que a categoria "sexo" também funciona como uma norma, além de ser "parte de uma prática regulatória que produz os corpos que governa”; assim, "toda força regulatória manifesta-se como uma espécie de poder produtivo". A "materialidade dos corpos", questão importante no trabalho da autora, tem a ver com o fato de essas normas regulatórias trabalharem em prol da construção da diferença e, consequentemente, na elaboração daquilo que Rich (2010) e Butler (2019) chamam de "heterossexualidade compulsória". 
A cisheteronormatividade, norma que estabelece como normal e inteligível apenas os corpos de pessoas cisgênero, heterossexuais, brancas e magras se apresenta, portanto, como uma expectativa a qual devemos nos encaixar, uma lei "que regula e determina a impossibilidade de vida fora dos marcos", um lugar que "designa a base da inteligibilidade cultural através da qual se naturaliza corpos/gêneros/desejos e definirá o modelo hegemônico de inteligibilidade de gênero" (BENTO, 2008, p. 51). As normas de gênero, nesse sentido, "definirão o considerado 'real', delimitando o campo no qual se pode conferir humanidade aos corpos." (BENTO, 2008, p. 20).

Butler (2014, p. 254) assevera que se trata tanto de "um discurso restritivo" que insiste "no binarismo homem e mulher" como "atua no sentido de efetuar uma operação reguladora de poder que naturaliza a instância hegemônica e exclui a possibilidade de pensar sua disrupção". Preciado (2014, p. 127), por sua vez, entende que esse discurso, bem como suas práticas regulatórias, definidos como parte da "tecnologia sexual", funcionam como uma "espécie de 'mesa de operações' abstrata na qual se leva a cabo o recorte de certas zonas corporais como 'órgãos' (sexuais ou não, reprodutivos ou não, perceptivos ou não etc.)".

A partir dessa discussão bibliográfica que parte da configuração de pares de opostos, corpos normais e anormais, práticas sexuais válidas ou não, propomos nesse texto uma abordagem crítica da normalidade sistêmica que pontuamos nessas páginas introdutórias, apresentando um debate que consideramos urgente, mas que é invisibilizado tanto na sociedade de modo geral, como na agenda feminista: a gordofobia, especialmente quando este tipo de discriminação é baseado no peso, no tamanho e no formato do corpo, e direcionado às corpas femininas, tendo em vista que, examinando este assunto sob um ponto de vista crítico, vivemos em uma "ditadura da magreza" onde os corpos femininos são alvo privilegiado, segundo Silva (2019, p. 49), de “discursos que evocam um 'biocódigo de gênero' que lhe cai tão bem, que define parte do seu destino: continuar jovem, bonita e um objeto de sedução".

Compreendemos, nesse sentido, que nós mulheres gordas ocupamos uma posição de invisibilidade e, portanto, de vulnerabilidade no tocante a esse debate, invisibilizadas tanto por estarmos à margem dos padrões de corpo e de gênero normalizados, como por não termos nossas experiências e vozes legitimadas do ponto de vista do feminismo hegemônico. Propomos, então, uma reflexão sobre a urgência de feminismos voltados para a construção e ampliação do debate acerca da desestigmatização de corpas gordas, reinventando também nossas potencialidades de ruptura do estabelecido no que diz respeito ao sexo, desejo e aos prazeres.

\section{Feminismo gordo: uma nova proposta epistemológica}

Segundo Laura Masson (2007, p. 216), “[...] os feminismos são a forma que as feministas encontraram para agregar as diferenças que se manifestam através do enfrentamento [...]", isto é , houve a necessidade de elaborações teóricas e propostas 
políticas que materializassem a ideia de que o feminismo é uma crítica à própria cultura vigente no mundo contemporâneo. A teoria e a prática feminista apontam que, historicamente, várias formas culturais ocidentais foram e continuam sendo misóginas e que todas nós podemos recuperar algum episódio em nossas memórias no qual nos sentimos invadidas e constrangidas pelas "formas cotidianas da dominação masculina" (BIROLI, 2014, p. 43). Essa é uma prova "do grau em que a violência misógina condiciona a experiência feminina em sociedades como as nossas” (DAVIS, 2017, p. 43), de mulheres de todas as raças e classes sociais, independente de sua orientação sexual e nacionalidade.

Consideramos como misoginia não apenas uma forma de expressão explícita de ódio ou aversão, cujos alvos são as mulheres, mas também, como sugere Bloch (1995, p. 13), um modo de falar sobre as mulheres no qual "a mulher é o sujeito da frase e o predicado um termo mais geral”, no qual mulheres são transformadas em uma "essência que, enquanto essência, é eliminada do palco histórico do mundo".

Não foi à toa que, na década de 1960, a bandeira "o pessoal é político" ganhou vulto, politizando o privado, "desfazendo as tradicionais barreiras que opõem o público-masculino ao privado-feminino” e, com isso, assumiu-se a discussão pública de aspectos da sexualidade (RAGO, 2001, p. 64). Essa bandeira, apropriada como um slogan pelas gerações seguintes, propunha um importante questionamento do conceito de "político" "rompendo assim com os próprios limites do conceito, até então identificado pela teoria política com o âmbito da esfera pública e das relações sociais que aí acontecem, isto é, do campo da política" (COSTA, 2005, p. 10 apud GALETTI, 2014, p. 2202). Afirmar que o que faz parte do âmbito pessoal é político significa, além da ressignificação do conceito de "político" e também da "própria forma de entender a política”, trazer para o centro do debate os dilemas femininos específicos da esfera privada, tais como os vários tipos de violências sofridas por nós mulheres nos mais diversos espaços, "quebrando a dicotomia público-privado base de todo o pensamento liberal sobre as especificidades da política e do poder político (COSTA, 2005, p.10)" (GALETTI, 2014, p. 2202), promovendo uma busca coletiva para as soluções desses problemas.

Gazire Lemos (2009) e Baer (2016) afirmam que as reivindicações feministas passaram por uma renovação com o advento das tecnologias eletrônicas, isto é, com as novas tecnologias da informação e da comunicação, por estas propiciarem ampliação de sua voz e visibilidade, especialmente de formas de utilização do corpo como ferramenta política. Novas experimentações foram possibilitadas, assim como uma gama de novidades na prática e na teoria feminista, que foram expandidas e fragmentadas pelas tecnologias comunicativas. Dessa maneira, os feminismos emergem situados em condições particulares que se desenvolvem por meio da vida cotidiana de mulheres em contextos sociais específicos, a saber: mulheres gordas da América Latina, precisamente do Brasil.

Esse olhar mais peculiar aos problemas enfrentados por grupos de mulheres localizados em todos os lugares e situações na sociedade foi importante para a visualização de sujeitos subalternos, tanto como reconhecimento político, como nas 
análises teóricas. Segundo Masson (2007), essa condição impulsionou o feminismo para a construção de estudos inovadores, apresentando complexos problemas de condições sociais não percebidos nem estudados anteriormente. Sendo assim, uma das características mais notáveis sobre os feminismos atuais é a capacidade de acumular estudos, discussões e práticas que podem chegar a níveis cada vez mais profundos de compreensão:

[...] das multiplicidades de configurações do sexo, gênero, classe, raça, etnia e inúmeras outras condições sociais que se articulam em organizações sociais, culturas e ideologias. Nessa busca emergiu a criatividade, imaginação, transgressão, vontade de viver, história, poderes, formas de fazer política e as concepções de mundo próprias das pessoas oprimidas na luta por sua emancipação (SANDOVAL, 2015, p. 116).

Apesar de as lutas feministas, no mundo atual, abrangerem muitas questões, espaços e contextos distintos, existe uma recorrente preocupação que permeia grande parte dessas pautas: resistir à pressão estética e de normatização aos corpos femininos, de que a mulher deve ser responsável e autônoma, no que se refere ao próprio corpo, já que este tem sido foco da opressão sistêmica machista desde sempre (JIMENEZ-JIMENEZ, 2020, p. 16). O “direito ao corpo" representa uma pauta muito explorada atualmente, um elemento comum e universal do movimento, o qual insere na "ordem do dia" reflexões sobre a sexualidade feminina, opção sexual, masturbação e orgasmo.

Esse período de significativas mudanças, ocorridas entre as décadas de 1960 e 1970 no ocidente, foi caracterizado principalmente pela emancipação sexual das mulheres e pela afirmação de igualdade entre os sexos. As novas invenções tecnológicas, como o advento da pílula anticoncepcional (no início dos anos de 1950) e a descoberta de antibióticos que tratavam as doenças sexualmente transmissíveis (a partir de 1941) e com a divulgação do preservativo de látex na década de 1930, as mulheres tomaram o controle da função reprodutora do seu corpo e se livraram da submissão masculina neste aspecto. Essa revolução sexual marcou, de certa maneira, o fim do patriarcado, da censura, assim como o progresso na igualdade das mulheres nas legislações nacionais. Toda essa revolução sociocultural, também, acarretou um deslocamento da atenção de muitas artistas, críticas e historiadoras, para o problema da construção social de uma identidade feminina. $\mathrm{Na}$ sua maior parte, essas mulheres acreditavam que tanto a teoria como a prática deveriam colaborar para mudar o modo como compreendemos nosso passado e, ao mesmo tempo, como reelaboramos nosso presente (ALMEIDA, 2010, p. 63). 
O rompimento com padrões e opressões que o corpo feminino sofre é uma pauta antiga do feminismo, porém, quando se trata da pauta gordofobia, existem algumas discordâncias entre as militantes e, infelizmente, a urgência e atenção necessárias a essa discussão ainda não é efetiva como deveria.

As primeiras discussões sobre o corpo gordo feminino que encontramos na literatura ligada à gordofobia aparecem no livro Fat is a feminist issue ("Gordura é uma questão feminista”), de Susie Orbach, publicado em 1978. A autora comenta:

A pressão é tamanha que, na minha experiência, o que percebi nos últimos 30 anos é que o comportamento, que antes era diagnosticado como um distúrbio, hoje é aceito como normal. É chocante. Antes as pessoas me procuravam porque sentiam que tinham um problema, relutavam em admitir e, por fim, queriam se curar. Atualmente, elas já chegam no consultório sabendo que têm um distúrbio e não têm intenção alguma de se curar. Querem apenas aprender a conviver com a doença (ORBACH apud LEMOS, 2012).

Gordofobia, palavra que nomeia a discriminação direcionada ao corpo das pessoas gordas, se trata de um neologismo que apenas recentemente se incorporou em dicionários formais da língua portuguesa - embora não em todos (ARRUDA, 2019). O termo também tem se popularizado nas redes sociais e tem sido pauta de debates em eventos e pesquisas acadêmicas transdisciplinares. Inspirado na versão em inglês fatfobia, o termo surgiu no contexto do ativismo de pessoas gordas norteamericanas, a partir de um debate que vem, aos poucos, ganhando espaço desde a década de 1970, como consequência da criação, em 1969, da NAAFA - National Association to Advance Fat Acceptance (Associação Nacional para o avanço da aceitação da gordura dos (as) gordos (as)) e também com a expansão dos fat studies, "de onde saíram os primeiros estudos sobre o tema", com o intuito de "questionar e lutar contra a estigmatização para com o grupo de pessoas gordas" (RANGEL, 2018).

Mas isso não quer dizer que este tipo de discriminação não existisse antes de ser nomeado, ou que ela não estivesse ou esteja presente no cotidiano das pessoas, ainda que não tenham acesso a essa terminologia.

Para mim, na época em que eu era apenas uma criança "gordinha demais para minha idade", assim como para tantas outras mulheres adultas que também foram meninas gordas, a discriminação por não apresentar um corpo normalizado era algo que fazia parte da rotina, ainda que não tivesse um nome. Era algo que se manifestava na forma como eu tinha minha alimentação controlada e como era forçada a tomar sopa no jantar porque "era mais saudável”, e como recebi apelidos que remetiam ao formato e ao tamanho do meu corpo, pelos membros da minha família; na escola, em contato com as outras crianças, que encontravam no 
meu corpo motivos para piadas e novos apelidos, que associavam meu corpo com animais grandes, como baleia e elefante; no consultório de nutricionistas e/ou endocrinologistas quando, com aproximadamente sete anos de idade, fui aconselhada a fazer a primeira de muitas dietas que fiz na vida, para que não corresse o risco de me tornar uma adulta gorda e feia (Marcelle, 31 anos, $2020)^{2}$.

Aprendemos, ainda na infância, que ter um corpo gordo e grande é ruim, que a única saída para a resolução deste "problema" é emagrecer e, com isso, passamos a sentir culpa por não correspondermos ao que a sociedade espera de nós (JIMENEZJIMENEZ, 2020). Com o tempo, acreditamos nisso como se fosse uma verdade absoluta e inquestionável e aceitamos que o problema está no nosso corpo, e não lá fora, na sociedade. Passamos a cultivar culpa, medo e vergonha por permanecermos com esse corpo que ninguém quer ter e nem querem que tenhamos.

É comum ouvirmos ou lermos pessoas gordas narrando experiências humilhantes que vivenciaram em casa, no trabalho, na rua, em transportes públicos, em hospitais, em aviões, em lojas de vestuário, por serem "pesadas demais" e/ou não caberem em roupas, cadeiras, poltronas, catracas, elevadores etc. É comum, também, isso ser transformado em piada e/ou meme, assim como é mais comum ainda que essas pessoas, por estarem cansadas do tratamento indiferente, medo e nojo, comecem a desenvolver ansiedade, depressão, síndrome do pânico e, que um dia, decidam não sair mais do quarto, escondendo-se dentro de casa - ainda que, nem sempre sua casa seja um lugar seguro (JIMENEZ-JIMENEZ, 2020), para evitar a dor e o sofrimento que sentem ao entrarem em contato com o mundo lá fora, este que aponta para o corpo gordo como sendo inapropriado (SANT'ANNA, 2013), portador de um excesso, mesmo que tratar dessa forma o corpo de alguém seja uma prática de desumanização.

A gordofobia atinge homens e mulheres, porém constatamos que ela atinge com maior força e alcance os corpos femininos. Desse modo, a questão antigordofobia, em nossa sociedade, passa necessariamente pela discussão feminista, mesmo que, pessoalmente, não se identifique esta ligação. O que queremos dizer é que a luta por consciência sobre o próprio corpo e emancipação de um sistema que lhe faz infeliz é uma reivindicação feminista, e mesmo que apenas mulheres gordas que sofrem dessa opressão mais profundamente consigam identificar a gordofobia em primeira pessoa, é uma luta urgente e necessária, já que a gordofobia mata, humilha e exclui milhões de mulheres todos os dias, além de estar socialmente imposta como um dispositivo de controle sobre nossos corpos.

A pauta sobre gordofobia levanta questionamentos de acessibilidade, estigma e muitas exclusões, mas também propõe reflexões sobre opressão estética, saúde, sexo e consumo, temas pertinentes ao feminismo desde seu surgimento, antecedendo inclusive a terminologia.

2 Depoimento de uma das autoras. 
Jussara Reis Prá (2014, p. 182) explica que "A consciência feminista vai além da história do movimento em si ou de determinados grupos envolvidos na luta pela emancipação feminina". Segundo a autora, existem muitas mulheres que defendem pautas feministas, mas não se autodeclaram feministas ou mesmo nem sabem nem se reconhecem como parte do movimento.

Quando uso a expressão "paixão da experiência”, ela engloba muitos sentimentos, mas particularmente sofrimento, pois existe um conhecimento particular que vem do sofrimento. É um modo de conhecer que muitas vezes se expressa por meio do corpo, o que ele conhece, o que foi profundamente inscrito nele pela experiência. Essa complexidade da experiência dificilmente poderá ser declarada e definida a distância. É uma posição privilegiada, embora não seja a única nem, muitas vezes a mais importante a partir da qual o conhecimento é possível (HOOKS, 2017, p. 124).

Segundo Prá (2014, p. 172), qualquer um que seja contra a inexpressiva participação das mulheres na política, ou contra o feminicídio, ou a pressão que existe sobre nossos corpos, ou a desigualdade salarial entre homens e mulheres, defende pautas feministas, já que, historicamente, o feminismo garante ou procura a garantia da igualdade entre homens e mulheres, tanto na participação quanto em qualquer outro lugar na sociedade. Isto é, “o feminismo é uma posição política que busca entender a subordinação das mulheres e encontrar estratégias para enfrentar a discriminação".

O feminismo gordo vem despontando na América Latina e no Brasil a passos largos, com representações de muitas corpas e propostas subalternas. Considerando o surgimento de "novos feminismos", vamos aprendendo com outros ativismos de mulheres, que é possível, necessário e revolucionário criarmos teorias a partir de corpos marcados pela dor, humilhação e exclusão, transformando todo ódio e raiva à sociedade em luta e, a partir dessas experiências, nos posicionarmos no mundo de outra maneira, de modo que viver seja um ato revolucionário (JIMENEZ-JIMENEZ, 2020).

Mulheres gordas latino-americanas começam a se organizar pela internet e em coletivos para pensarem e discutirem ferramentas construídas ao longo da vivência no mundo a partir de uma corpa gorda que sofre gordofobia desde sua infância. A gordofobia é um estigma cultural, estrutural e institucional em que as pessoas odeiam e evitam, de todas as maneiras, possuírem ou conviverem com corporeidades gordas.

Em novembro de 2019, o coletivo feminista gordo "gordas sin chaqueta", em Bogotá (Colômbia), organizou o primeiro Encontro do ativismo gordo na América Latina, intitulado "GRR Gordes, Resistencia y Rebeldia - 1er Encuentro de Activismos GordeS del Abya Yala y la Diáspora Africana". Uma das autoras esteve em sua 
organização e pode participar de perto de todo o processo, organização e encontros com outras mulheres gordas que fazem ativismo em seus respectivos países.

Um dos eixos temáticos do encontro foi sobre gordura e desejo, no qual as participantes do encontro conversaram sobre como o desejo, em sociedade, é heteronormativo e colonial e como nossos corpos dissidentes não entram nessa concepção hegemônica de desejar e ser desejado. Foi mencionado o "Manifesto da Ternura Radical”, por Dani D’Emilia e Daniel B. Chávez (2015), que propõe outras maneiras de sentir e cuidar de outra pessoa, e de libertar-se dessa construção sobre o amor patriarcal, em que só os homens se favorecem nas relações, ou onde o ato de querer o outro é egoísta e opressor.

Numa construção descolonial, a proposta é construir outras maneiras de desejo e principalmente de relações afetivas através da arte e da criatividade. Pensar numa outra maneira de desejar e ser desejada é libertador, porque nossos corpos não estão no padrão de desejo patriarcal. Assim, reconstruir essa forma de se relacionar é curativo, estratégico e redentor.

A partir de nossas vivências, é possível reinventar o jeito de estar no mundo. É um processo demorado e lento, mas existem mulheres como nós, consumindo e fazendo ativismo numa nova proposta de (re) entender seu corpo gordo em sociedade e consigo mesmas, na preocupação de recriar saberes que não mais patologizem e matem corpas gordas.

O feminismo gordo denuncia, portanto, uma injustiça epistêmica sobre nossos corpos e contrapõe a estigmatização dessas mulheres socialmente, na despatologização dessas corporeidades e no silenciamento, na perda do acesso à sexualidade como sujeito participante de suas próprias práticas sexuais, desejos e prazeres.

\section{Sexo, desejo e prazeres revolucionários}

Corpos que não estão dentro da classificação do que a sociedade capitalística entende como normativo, estão fora da concepção do que se é desejável ou possa sentir ou dar prazer, dentro de uma reprodução da naturalização dos corpos e práticas sexuais considerados "normais", “desejáveis" e que sentem e causam "prazeres". Ou seja, os corpos gordos são patologizados, já que o entendimento social é que toda gorda é doente, anormal, assexuada, feia, etc.

A categoria do "sexo" é, desde o início, normativa: ela é aquilo que Foucault chamou de "ideal regulatório". Nesse sentido, pois, o "sexo" não apenas funciona como uma norma, mas é parte de uma prática regulatória que produz os corpos que governa, isto é, toda força regulatória manifesta-se como uma espécie de poder produtivo, o poder de produzir - demarcar, fazer, circular, diferenciar — os corpos que ela controla. (BUTLER, 1999, p. 151). 
Mulheres gordas podem romper com a normalização heterocentrada, não se submetendo ao contrato social da reprodução colonizadora, reexistindo e reinventando seu lugar sexual no mundo. Essas corpas estão dentro de outra lógica/ estrutural em nossa sociedade, pois é considerada contraprodutiva. Basta observar vários discursos de poder: biomédicos, educacionais, políticos, midiáticos, entre outros, que reverberam a ideia que a mulher gorda não pode ter filhos, precisa emagrecer para reproduzir, para se encaixar num corpo que precisa ser produtivo e reprodutivo. Posto isso, propomos pensar as corpas gordas como "formas de prazer-saber alternativas à sexualidade moderna” (PRECIADO, 2014, p. 22). Como sexualidades "perversas" que perturbam a ordem desse contrato cisheterocentrado do desejo.

As corpas gordas rompem com esse cânone sobre o prazer, e como explica Preciado (2014), entramos numa contrassexualidade, onde na revolução de se permitir ser um corpo dissidente, subalterno, possa descobrir por si mesma, outras formas de prazeres e desejos. O controle político sexual hegemônico é, então, rompido. A proposta está na desconstrução do que sempre foi negado a esses corpos: o prazer. A partir desse entendimento, uma reconstrução como ação política através da contestação do que aprendemos sobre sexo, pornografia, desejo e prazer, pode ser construído. É uma revolução com o próprio corpo gordo como desejável e que também goza, porque pode construir outra lógica no que cabe ao desejo e prazer.

Ultrapassar a normalização das identidades sexuais, para além do que o regime político vigente fez com os corpos “abjetos” como nossas corpas gordas, é propor uma nova maneira de estar no mundo. Seguindo essa discussão, a ideia é uma desobediência sexual política dos "anormais", "indesejáveis", "subalternos e dissidentes".

A sexopolítica é uma das formas dominantes da ação biopolítica no capitalismo contemporâneo. Com ela, o sexo (os órgãos chamados "sexuais", as práticas sexuais e também os códigos de masculinidade e de feminilidade, as identidades sexuais normais e desviantes) entra no cálculo do poder, fazendo dos discursos sobre o sexo e das tecnologias de normalização das identidades sexuais um agente de controle da vida. (PRECIADO, 2011, p. 11).

Reverteremos essa lógica, no que cabe ao prazer ser reconstruído, o desejo de dentro para fora, a partir do próprio corpo, transformando a normalidade sistêmica em uma revolução política das corpas gordas, onde eu escolho construir e dar prazer. Essa proposta vem ao encontro de formas subalternas de sobrevivência, ressignificando nosso lugar sexual nos regimes de poder. Reinventando nosso lugar na sexualidade como dispositivo fundamental na constituição da ordem no mundo que odeia as corpas gordas. (BALLESTRIN, 2017). 


\section{Considerações finais}

Na sociedade capitalista contemporânea, as mulheres gordas são inferiorizadas e humilhadas socialmente, através de vários discursos e práticas hegemônicos de poder que classificam seus corpos como doentes, feios e indesejados, como se essas mulheres não tivessem direito de se reivindicarem como sujeitos desejantes e desejáveis.

No entanto, existe uma proposta sexopolítica, como anunciada no texto, de romper com o entendimento sexual heteronormatizado e propor uma descolonização da sexualidade, construindo outras práticas, outras corporeidades, outros projetos políticos do desejo.

É de suma importância que feminismos subalternos, como os das gordas, se levantem, se analisem e rompam com essa naturalização dos prazeres, no qual não mais se submetam à reprodução compulsória, como contrato social heterocentrado com caráter colonial civilizador.

O feminismo gordo chega para denunciar a injustiça epistemológica que exclui esses corpos, desejos e prazeres. Nossa proposta é sobre uma desobediência sexual que rompe com as tecnologias de normalização das identidades sexuais, já que se re(inventam) como corpos políticos ressignificadores de suas exclusões normativas de sexualidade, se colocando no mundo com práticas subalternas, a partir de propostas de outros modos de subjetivação e sexualidade dentro de um posicionamento revolucionário de quebras de paradigmas.

\section{Referências Bibliográficas}

ALMEIDA, Flávia Leme de. O feminino na arte e a arte do feminino: movimentos libertários do século. In: ALMEIDA, Flávia Leme de. Mulheres recipientes: recortes poéticos do universo feminino nas artes visuais. São Paulo: Editora UNESP; São Paulo: Cultura Acadêmica, 2010, p. 55-73.

ARRUDA, Agnes de Sousa. O peso e a mídia: uma autoetnografia da gordofobia sob o olhar da complexidade. Tese (Doutorado em Comunicação). São Paulo: Universidade Paulista, 2019.

BAER, Hester. Redoing feminism: digital activism, body politics, and neoliberalism. Feminist Media Studies, v. 16, n.1, 2016, p. 17-34.

BALLESTRIN, Luciana Maria de Aragão. Feminismos Subalternos. Rev. Estud. Fem., v. 25, n. 3, 2017, p. 1035-1054.

BENTO, Berenice. O que é transexualidade. São Paulo: Brasiliense, 2008. 
BIROLI, Flávia. O público e o privado. In: MIGUEL, Luis Felipe; BIROLI, Flávia. Feminismo e política: uma introdução. São Paulo: Boitempo, 2014.

BLOCH, R. Howard. Misoginia medieval e a invenção do amor romântico ocidental. Rio de Janeiro: Ed. 34, 1995.

BUTLER, Judith. Corpos que pesam: sobre os limites discursivos do 'sexo'. In: LOURO, Guacira Lopes. O corpo educado: pedagogias da sexualidade. Belo Horizonte: Autêntica, 1999, p. 151-168.

BUTLER, Judith. Regulações de gênero. Cad. Pagu, n. 42, jun. 2014, p. 249-274.

DAVIS, Angela. Mulheres, cultura e política. São Paulo: Boitempo, 2017.D’EMILIA, Dani; CHÁVEZ, Daniel. Manifiesto Vivo: Ternura Radical, 2015.

GALETTI, Camila Carolina H. Feminismo em movimento: A Marcha das Vadias e o movimento feminista contemporâneo. In: Anais do 18o REDOR. Recife: UFRPE, 2014, p. 2196-2210.

GAZIRE LEMOS, Marina. Ciberfeminismo: Novos discursos do feminino em redes eletrônicas. Dissertação (Mestrado em Comunicação e Semiótica). São Paulo: Pontifícia Universidade Católica de São Paulo, 2009.

GOLDENBERG, Mirian. (Org.). Nu e vestido: dez antropólogos revelam a cultura do corpo carioca. 2. ed. Rio de Janeiro: Record, 2007.

HOOKS, bell. Ensinando a transgredir: a educação como prática de liberdade. São Paulo: Editora WMF Martins Fontes, 2017.

JIMENEZ-JIMENEZ, Maria Luisa. Lute como uma gorda: gordofobia, resistências e ativismos. Tese (Doutorado em Estudos de Cultura Contemporânea). Cuiabá: Universidade Federal de Mato Grosso.

LEMOS, Nina. Susie Orbach. Revista TPM, 2012. Disponível em: https://revistatrip. uol.com.br/tpm/susie-orbach. Acesso em: 13 mai. 2021.

LOURO, Guacira Lopes. Um corpo estranho: ensaios sobre sexualidade e teoria queer. Belo Horizonte: Autêntica Editora, 2004.

MASSON, Laura. Feministas en todas partes. una etnografía de espacios y narrativas feministas en Argentina. Buenos Aires: Prometeo libros, 2007. 
PRÁ, Jussara Reis. Mulheres, direitos políticos, gênero e feminismo. Cadernos Pagu, n. 43, jul./dez. 2014, p. 169-196.

PRECIADO, Paul Beatriz. Multidões queer: notas para uma política dos anormais. Rev. Estud. Fem., v. 19, n. 1, jan./abr. 2011, p. 11-20.

PRECIADO, Paul Beatriz. Manifesto contrassexual: práticas subversivas de identidade sexual. São Paulo: n-1 edições, 2014.

PRECIADO, Paul Beatriz. Testo Junkie. sexo, drogas e biopolítica na era farmacopornográfica. São Paulo: n-1 edições, 2018.

RAGO, Margareth. Feminizar é preciso: por uma cultura filógina. São Paulo em Perspectiva, v. 15, n. 3, 2001, p. 53-66.

RANGEL, Natália Fonseca de Abreu. O ativismo gordo em campo: política, identidade e construção de significados. Dissertação (Mestrado em Sociologia Política). Santa Catarina: Universidade Federal de Santa Catarina, 2018.

RICH, Adrienne. Heterossexualidade compulsória e existência lésbica. Bagoas Estudos gays: gêneros e sexualidades, v. 4, n. 5, nov. 2010, p. 17-44.

SANDOVAL, Chela. Metodología de la emancipación. México: PUEG, 2015.

SANT'ANNA, Denise Bernuzzi de. Entre o peso do corpo e o pesar da alma: notas para uma história das emoções tristes na época contemporânea. História. Questões e Debates, Curitiba, n. 59, jul./dez. 2013, p. 99-113.

SILVA, Marcelle Jacinto da. "Ame seu corpo, inclusive sua vagina”: estudo sociológico da produção discursiva sobre a "autoestima vaginal" e "empoderamento feminino" nas mídias digitais. Tese (Doutorado em Sociologia). Fortaleza: Universidade Federal do Ceará, 2019.

VERGUEIRO, Viviane Simakawa. Por inflexões decoloniais de corpos e identidades de gêneroinconformes:umaanáliseautoetnográficadacisgeneridadecomonormatividade. Dissertação (Mestrado em Cultura e Sociedade). Salvador: Universidade Federal da Bahia, 2015.

Recebido em 22/07/2020.

Aceito em 20/05/2021. 